\title{
ANTECEDENTES METAFÍSICOS DEL CONCEPTO SER DE SARTRE
}

\author{
Juan Camilo Hernández Rodríguezy \\ Cristhian Alexander Baracaldo Méndez* \\ doi: 10.11144/Javeriana.uph35-71.amss
}

\section{RESUMEN}

En el presente trabajo analizaremos algunos de los principales elementos de la propuesta ontológico-fenomenológica que Sartre expone en $E l$ ser y la nada, relacionándolos con algunos referentes clave (principalmente, Parménides, Hegel, Husserl y Heidegger). Al aclarar los vínculos de esta propuesta con la tradición filosófica previa sobre el tema del ser, su papel en la existencia, el carácter de la realidad y su relación con el fenómeno se demuestra cuál es el verdadero aporte de Sartre en esta materia.

Palabras clave: ser; nada; existencia; realidad; fenómeno

\footnotetext{
Universidad Pedagógica Nacional, Bogotá, Colombia - Universidad Santo Tomás, Bogotá, Colombia. Correo electrónico: 1f_jchernandezr540@pedagogica.edu.co - cristhianbaracaldo@usantotomas. edu.co

Para citar este artículo: Hernández Rodríguez, J. C., \& Baracaldo Méndez, C. A. (2018). Antecedentes metafísicos del concepto ser de Sartre. Universitas Philosophica, 35(71), pp. 323-349. ISSN 0120-5323, ISSN en línea 2346-2426. doi: 10.11144/Javeriana.uph35-71.amss
} 


\title{
METAPHYSICAL PRECEDENTS OF SARTRE'S CONCEPT OF BEING
}

\begin{abstract}
In this work we will analyze the main features of Sartre's ontologicalphenomenological theory in Being and Nothingness, linking them with some key historical precedents (mainly, Parmenides, Hegel, Husserl and Heidegger). By clarifying the connections of this theory with the former philosophical tradition on the subject of Being, its role in existence, reality's nature and its relation to the phenomenon, the actual contribution of Sartre in this matter is demonstrated.
\end{abstract}

Keywords: being; nothingness; existence; reality; phenomenon 


\section{Introducción}

Cuando Sartre dio su conferencia (posteriormente publicada a modo de libro) El existencialismo es un humanismo recibió fuertes críticas por parte de sus lectores, dirigidas a su sistema y especialmente a su obra El ser y la nada. Desde ese momento hasta hoy muchos críticos han centrado su atención en temas como la libertad, el otro y la mala fe; sin embargo, parece que el tema del ser y de la nada -su aporte ontológico-metafísico- ha sido relegado. Causa de ello, a nuestro juicio, es la falta de comprensión de esta parte de su teoría.

A continuación, intentaremos explicar la relación que hay entre el concepto ser de Parménides y de Sartre a través de la elaboración de "lo que se piensa" y "lo que es". Por otra parte, se mostrará cómo Sartre logra reconciliar a la fenomenología con su corriente crítica paralela (la ontología) a partir de las relaciones fenómeno-ser, existencia-realidad y subjetividad-objetividad, sin caer en solipsismos, panteísmos, reduccionismos o misticismos, entre otros.

Desde la primera parte de El ser y la nada: ensayo de ontología fenomenológica, Jean-Paul Sartre hace referencia al $\operatorname{ser}^{1}$ (no en vano está en el título del texto y, a la vez, en el título de la introducción: "En busca del ser"). Surge así la pregunta: ¿desde dónde quiere nuestro autor "buscar" el ser? Sartre aborda el ser desde la

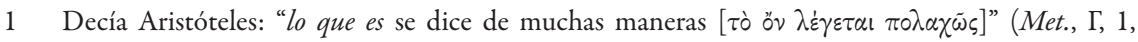
1003a20). Ciertamente, el término ser es polisémico en la tradición metafísica. He aquí algunos usos: 1. Como predicamento/fundamento de predicación ( $\tau \tilde{\omega} \nu \lambda \varepsilon \gamma \dot{o} \mu \varepsilon v \omega \nu)$ (Cat., 2a11); v. gr:: "Juan es alto" o "2+2 es 4". 2. Como lo que existe; v. gr: "Yo soy, yo existo" (Descartes, 2014, AT,

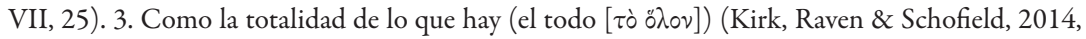
p. 326). 4. Como nombre propio para referirse a Dios como dador de la existencia de los demás entes (Aquinatis, $S T$, I, q. 3, a. 4, sol.; q. 44, a. 1, sol.); 5. Como la equivalencia de la expresión tal ente, v.gr: el ser humano, el ser vivo, etc. 6. En los casos donde se menciona al ser en alguna forma de determinación (Bestimmung) v.gr:. "ser en-si", "ser para-si" (Hegel, 2017). En la traducción al español de Juan Valmar de El ser y la nada (Sartre, 1993) se utiliza indistintamente el término ser con mayúscula y minúscula. Creemos que en la mayoría de los casos Sartre se refiere a la segunda y sexta definición (y a modo de hipótesis, a la tercera). No consideramos adecuado utilizar la mayúscula inicial porque en el español esta solo se usa para los nombres propios y solo en el cuarto caso se cumple este requisito (Dios). Dado que Sartre (2007) sostiene que su existencialismo es ateo (p. 30), no usaremos esta mayúscula. 
tradición filosófica de la ontología y la fenomenología; es por ello que, antes de comenzar a adentrarse en su pensamiento, es menester entender previamente algunos presupuestos hegelianos, heideggerianos y husserlianos que inciden en la argumentación de Sartre en tanto premisas tácitas, principios subyacentes a sus definiciones, y métodos. Abordar la discusión histórica es, pues, la base de una crítica sobre la relevancia, el impacto y la rigurosidad de esta obra de Sartre.

Por otra parte, es paradójico que Sartre haya tenido el anhelo de alejarse de la filosofía de sus maestros para hacer una propia. Así lo expresó en las Cartas al Castor $(1986)^{2}$, el 21 de enero de 1940, apenas tres años antes de la publicación de El ser y la nada:

Creo que es realmente interesante y novedoso, lo que estoy haciendo, ya no tiene nada de filosofía husserliana, ni de Heidegger ni de nada. Se parecería más bien a todas mis viejas ideas sobre la percepción y la existencia, ideas muertas antes de nacer, por falta de técnica, pero que actualmente puedo tratar con toda la técnica fenomenológica y existencialista (p. 32).

En efecto, al final no logra tomar dicha distancia: su obra $-\mathrm{y}$, en particular, esta (que es posterior a su primer ciclo) - se basa en el modelo de la fenomenología husserliana, la ontología heideggeriana y la metafísica de Hegel, escuelas que fueron materia esencial de sus estudios en Berlín desde 1933. De esta estancia Sartre recoge los elementos de su propia fenomenología existencial y el carácter metafísico que lo acompañaría el resto de sus días.

VARIAS INTERPRETACIONES se han dado a lo largo de la historia al término metafisica $(\tau \tilde{\omega} \nu \mu \varepsilon \tau \grave{\alpha} \tau \dot{\alpha} \phi v \sigma \kappa \dot{\alpha})^{3} \mathrm{y}$, desde esta perspectiva, del término ser. Tal

2 "Castor" es la manera en que llamaba Jean-Paul Sartre a Simone de Beauvoir, la mujer que lo acompañó en gran parte de su camino filosófico y vital; de hecho, es a ella a quien dedica Lêtre et le néant: Essai d'ontologie phénoménologique (1943).

3 El adverbio metá ( $\mu \varepsilon \tau \dot{\alpha})$ en esta unión de palabras, más que interpretarse como lo que está 'más allá, debe entenderse como lo que está 'en medio, entremedias o juntamente' de lo que ya está

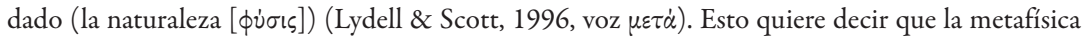
es el estudio de aquello que está en medio de, que subyace, es decir, lo que está por debajo/detrás 
como lo expresa Ferrater Mora (1975): "a veces, se entiende el ser como la esencia; a veces, como la existencia; a veces, como el ente; a veces como la substancia" (t. 2, p. 652, voz metafísica). Puesto que el objeto de estudio de la metafísica se manifiesta de muchas maneras (Met., $\Delta, 7,1017 \mathrm{a} 7-9)$, ser puede entenderse como verbo o como sustantivo; la diferencia se hace patente cuando vemos el ser como una entidad o sujeto ( $v$ gr., el ser humano), o cuando lo vemos como el modo de ser de algo (v.gr.: ser honesto). Gramaticalmente, ser es una condición predicativa fundamental (Cat., 2a11 y ss.), mientras que ontológicamente tiene una acepción existencial. En este sentido, se amplían los horizontes de posibilidad del término y la disputa que nace se centra en decidir si el ser es una cuestión ontológica (lo que está en), lógica (como condición de predicación), teológica (el Ser como Dios) (Aquino, 1963, c. 4, §33) o gnoseológica/epistemológica (el ser como realidad) en Hegel (2017, $\$ \$ 89-95)$.

Según lo anterior, se puede inferir que la preponderancia del ser se encuentra en el estudio de la metafísica; aquella que fue designada por Aristóteles como fi-

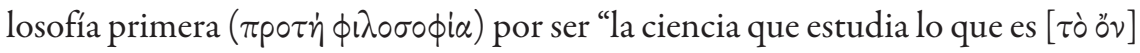
en tanto que algo que es [ $\tau \grave{\partial} \partial ै \nu]$, y los atributos que por sí mismo le pertenecen" (Met., 1003a20). La metafísica viene a ser la ciencia de lo que es ( $\tau$ ò öv) por tener el objeto de estudio más extenso e incomprensible, pero, a su vez, más cercano: el ser (Heidegger, 2014, I, $\$ 1$ ). Es por todo esto que la pregunta por el ser le es natural al hombre (por su "cercanía" con el ser); de hecho, es y ha sido su pregunta primera, la pregunta de base de la filosofía y del pensamiento en cuanto tal.

Aquí es, pues, donde se hace necesaria la metafísica, pues el hombre (en su género) siempre ha estado en una búsqueda por la verdad y por la realidad. Solo un análisis metafísico (filosófico) puede abordar cabalmente el problema del ser, evaluarlo desde su propia naturaleza. El análisis filosófico es importante porque pretende evaluar críticamente eso que es base del ser, sin importar los obstáculos lógicos (contradicciones), gnoseológicos (paradojas) o lingüísticos (aporías) con los que se encuentre al intentar caracterizarlo, pues en el pensamiento metafísico la complejidad del ser no es evadida y, mucho menos, reducida.

de lo superficial (Lewis, Short \& Freund, 1956, voz subicio) y que se pone en evidencia, esto es: su condición de existente por sí mismo, en tanto que substancia. 
Nacen, pues, cuestionamientos netamente existenciales ${ }^{4}:$ ¿es falso lo que experimentamos o lo que se nos ha dicho acerca de la vida o la existencia? ¿Es suficiente lo que llamamos realidad? Y ipretendemos crear o buscar una realidad distinta?

El origen de estas cuestiones comienza con los primeros pensadores griegos ${ }^{5}$ (llamados, por convención, gracias a Hegel, presocráticos); a estos se les suele atribuir el nacimiento de la filosofía misma, que en principio buscó relacionar al hombre con el mundo y darle un fundamento o determinar su existencia. De esta manera, su pensamiento dio y sigue dando cabida a múltiples interpretaciones de la realidad. Es el hombre griego quien se vio maravillado por la grandeza del

4 Existencia es un concepto clásico de la metafísica. En su sentido original, el concepto proviene del constructo ex-sistere que significa 'estar afuera de..., emerger, aparecer' (Lewis, Short \& Freund, 1956, voz exsisto). Este concepto fue utilizado por los autores cristianos para explicar la situación del ente respecto al Ser (que es Dios) (De Saint-Victor, 1958, IV, c. 12; f. 160b9-160c20). Si el ente es creado y preservado en su ser por su creador, entonces su esencia está supeditada previamente en una relación trascendente respecto al creador: su ser es ser incompleto, pues está fuera de Dios (de su mente). En la filosofía contemporánea, por otra parte, existir tiene una concepción distinta. Su énfasis no está en el ser o el origen absoluto del ente (Dios), sino que se enfoca en el existente mismo, en su forma de estar en el mundo y de asumir esa posicionalidad en él (ese "estar arrojado en el mundo"). "El ser mismo con respecto al cual el Dasein se puede comportar de esta o aquella manera y con respecto al cual siempre se comporta de alguna determinada manera lo llamamos existencia" (Heidegger, 2014, \$4, SZ, 12). Así, ese "salir/estar fuera de" ya no es teológico, sino antropológico; no se sale fuera de la mente de Dios, sino que "se sale fuera de sí" (Existenz). Si existencia no es una esencia adquirida a priori, sino que, al revés, el hombre construye su modo de existir, "lo que ellos tienen en común [Heidegger y Sartre] es simplemente el hecho de considerar que la existencia precede a la esencia, o, si se prefiere, que hay que partir de la subjetividad" (Sartre, 2007, p. 27).

5 Se podría objetar en este punto que ya había pensamiento y filosofía en Oriente -principalmente en China y en India-, y que, además, muchos de estos pensadores (como Tales, Heráclito o Pitágoras) sustentaron sus principios en dichas teorías. Ante lo segundo, es efectivamente cierta la influencia del pensamiento asiático (sobre todo, con los Upanișads); sin embargo, para estos autores, esto no necesariamente indica que esa influencia contenga de suyo un elemento diferenciador entre el pensamiento oriental y el occidental (y con esto se responde el primer punto): la re-flexión del pensamiento. ¿Qué quiere decir esto? Las propuestas del taoísmo, el brahmanismo, etc., al menos desde las perspectivas de Heidegger (2004) y Husserl $(2008$, \$ $\$$ ) (pero no las nuestras), son propuestas en las que el pensamiento no es evaluado por sí mismo; es decir, no se pregunta a sí mismo ¿por qué esto que he dicho es así y no de otra manera? ¿Cuál es la causa de esto? ¿Lo que digo es aceptable para otros que no se comprometan con mis principios religiosos-naturalistas? Esta disposición se llamó después, de manera reduccionista, "racionalidad". No intentamos aquí negar la influencia de dicha corriente, sino que pretendemos caracterizar mejor nuestro tipo de pensamiento (re-flexivo) con referencia al punto de inflexión que ocurre en el pensamiento presocrático. 
cosmos y nos dejó los interrogantes de su propio principio $(\dot{\alpha} p \times \dot{\eta})$ y de su fin ( $\tau \dot{\varepsilon} \lambda \circ \varsigma)$. Es así como el periplo de la existencia humana se ve sumergido en estos problemas.

La historia nos ha legado estos cuestionamientos junto con la infinita curiosidad del hombre que, en principio, se analizó a sí mismo como una mera observación y se interpretó racionalmente como manifestación de seres superiores -deidades naturales que adquirieron un valor dentro del pensamiento-. La necesidad de pensar "lo múltiple" respecto a "lo Uno" (Plotino, 2006, VI, 1, 9) nos ha llevado a analizar ontológicamente la realidad. Es en la búsqueda insaciable de dar una respuesta concreta y plenamente objetiva a la pregunta de la realidad y la existencia donde emerge la disputa entre científicos, teólogos y filósofos; es, en último término, la pregunta sobre el sentido del ser determinado (Dasein $)^{6}$.

Partir en la búsqueda del ser es adoptar una visión occidental (griega), es una cuestión existencial. Es el encuentro del hombre con su existencia lo que lo hace

6 Entiéndase aquí das Dasein no en el sentido heideggeriano, sino en el hegeliano; no como el ser existente que se reconoce en cuanto tal ("ser-para-la-muerte"), sino que es la existencia que es producto del devenir entre el ser y la nada (Hegel, $2011[W d L], B$. I, S. 45). Este término es crucial en la ontología de Hegel, Heidegger y Sartre, solo que cada uno lo reorienta de una manera distinta. La relación de Sartre con estos dos filósofos (y también con Husserl) es latente, como lo afirma Verstraeten (1992, pp. 354-355), y no solo en El ser y la nada: esa relación con Hegel llega a su culmen en su Crítica de la razón dialéctica. Dasein (véanse notas al pie 8 y 14) significa, en su sentido más original, 'ser determinado' (ser abi [Fuentes Morán, 2002, voz Dasein]), es decir, un ser diferenciado, con cualidades, especificaciones, limites. El existente (Dasein) se distingue del puro ser en tanto que su afirmación no es absoluta, sino que está, en cierta medida, negada por la nada. Quizás el mejor ejemplo de esto es la corporalidad (nuestras dimensiones, colores, tamaños, razas, etc., son esas y no otras). El concepto de límite, según lo reconoce Verstraeten (1992) es una de las grandes herencias de Hegel a Sartre (y, siguiendo a Fell, 1979, nos atrevemos a decir que también a Heidegger), en particular en el concepto de finitud o infinitud de su filosofía. Efectivamente, el hombre (llamado por Hegel y Fichte el "espíritu subjetivo"), al estar determinado con ciertas condiciones (históricas) existenciales, afirma su "ser en-sî"; somos lo que somos porque nuestra cultura (espíritu objetivo) nos ha determinado de esta manera (con $x$ lengua, con $y$ creencias y $z$ conocimientos). Empero, esa misma limitación implícita en la determinación es precisamente el empuje que posibilita la alienación (negación del yo "en-si") para modificar eso que él en una primera instancia es. Esto es llamado por Hegel (2010a) "el despliegue del espíritu” y por Sartre (1993) la libertad. Consideramos que esta cita resume adecuadamente esta relación limitado-ilimitado y finito-infinito como condiciones ontológicas de posibilidad de la libertad: "habremos de ser lo que hagamos, con aquello que hicieron de nosotros” (Sartre, citado por Romero, 2005, p. 17). 
cuestionarse en todo momento; por ello, decimos que los pensadores griegos son nuestros padres en la filosofía; fue un pueblo metafísico por excelencia.

La expresión "filosofía europea occidental", que se oye con tanta frecuencia, es en verdad una tautología. ¿Por qué? Porque para Sartre, Heidegger, Husserl y Hegel la "filosofía” es griega en su esencia; ello significa que la filosofía es, en el origen de su esencia, de tal naturaleza que precisó del mundo de los griegos, y solo de este mundo, para iniciar su despliegue (Heidegger, 2004, p. 34).

Ahora bien, entender la filosofía sartreana tiene un alto nivel de complejidad debido a la inmensa tradición filosófica que le precede en la pregunta sobre el ser (Descartes, Berkeley, Kant, Hegel, Husserl, Heidegger, entre otros muchos). Así, iniciar por la pregunta del ser implica recoger toda una raigambre filosófica que, en el caso sartreano, supone una labor asidua y exigente.

En el presente trabajo realizaremos un análisis comparativo entre el concepto de ser de Parménides y el de Sartre porque: a) tal y como es usado en la tradición ya mencionada, tiene su origen en este pensador griego; b) de aquí se comprende cómo surge el concepto de totalidad ( $\tau$ ò ő̀ $\lambda$ ), que es esencial en la propuesta sartreana y la metafísica occidental; y c) porque analizar las raíces del concepto de ser en el contexto de la propuesta sartreana permitirá comprender cuál es su verdadero aporte y cómo se inserta Sartre en la discusión sobre la pregunta por el ser.

Diremos, entonces, que el ser sartreano es equiparable con el ser de Parménides $-y$ aquí nace nuestro primer escollo con la historia de la filosofía, debido a que es un tema bastante debatible- pues, como veremos, el ser parmenídeo en principio lo referimos al ser del pensamiento: "pues lo mismo es el pensar y

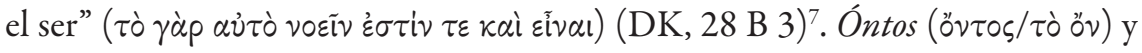

7 En adelante usaremos la traducción de Montero Moliner (1960) para citar el poema. En caso de requerir un contraste con otras traducciones, las citaremos por el nombre del traductor. Consideramos esta traducción como la correcta y no la de Eggers Lan \& Juliá (1981) -“pues ‘solo’ lo mismo puede ser y pensarse" (t. 1, p. 477)-, porque ese "solo" daría la impresión de que lo que dice Parménides es que solo lo idéntico y estable puede existir y ser pensado. No obstante, si bien esto sí lo afirma Parménides, este parágrafo es precisamente la justificación de por qué es necesario que el ser sea idéntico y estable: porque pensamiento y ser son una misma cosa. Igual traducción realiza Diels (1912): „Denn (das Seiende) denken und sein ist dasselbe“ (pues ser pensado y ser son lo mismo) (S. 152). Consideramos esta como la tesis central del poema. 
lógos ( $\lambda$ óyos) son uno solo, y es esta identidad lo que consolida "la verdad bien

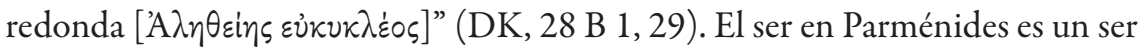
lógico que termina siendo ontológico, y en Sartre tiene un valor preponderante dicha identificación.

El poema de Parménides inicia haciendo referencia a un viajero que es jalado por caballos en un carruaje; dicho viajero es llevado en un camino guiado por doncellas. Se dice que es conducido ante la diosa "que lleva al mortal vidente a través de todas las ciudades" (DK, 28 B 1, 1). Es bastante interesante notar, en principio, cómo el poema nos muestra la visión epistémica del hombre griego en la que los dioses pueden brindar a los hombres la omnisciencia (que ellos poseen por su naturaleza divina). El conocimiento así entendido es algo tal vez místico, algo que solo es manifestado a unos pocos. El vidente se ve incitado a conocer la verdad'; sin embargo, es la diosa quien dará solución al problema del conocimiento. Dice la diosa, enseñándole al viajero:

Es preciso que conozcas todo, tanto el corazón imperturbable de la Verdad bien redonda, como las opiniones de los mortales, en las cuales no se halla la verdadera creencia. Pero aprenderás también estas cosas, cómo las apariencias ha sido necesario que sean probablemente, extendiéndose todas a través de todo (DK, 28 B 1, 25-30).

Así, aparte de la epistemología griega que profesa el eleata, lo que se nos muestra es una diferenciación al interior del problema del conocimiento, teniendo en cuenta que la apuesta epistémica se centra en el conocimiento de la verdad -que se equipara con el pensamiento y, obviamente, con el ser- y las opiniones de los mortales $(\delta \circ \xi \alpha)$, que corresponden a las apariencias o lo que no

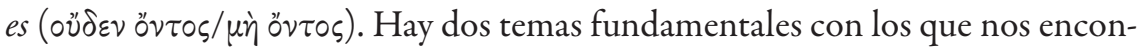

8 Esto es evidente en el término griego mismo: alétheia ( $\lambda \lambda \dot{\eta} \theta \varepsilon ı$ ): "lo que es develado". Esto es observado por Heidegger (1997): "el producir acontece solamente cuando llega lo velado a lo desvelado. Este llegar se mueve y descansa en lo que nosotros llamamos desocultar. Para designarlo los griegos tenían la palabra alétheia ( $\lambda^{\lambda} \dot{\theta} \theta \varepsilon i \alpha$ ). Los romanos la tradujeron por veritas. Nosotros decimos verdad, y la entendemos comúnmente como rectitud del concebir [representar: Vorstellen])" (p. 120). Esto es relevante porque, como se verá más adelante, en la propuesta sartreana la identificación verdad-realidad es crucial. Como hipótesis, afirmamos que la idea de Wirklichkeit

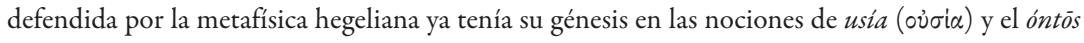

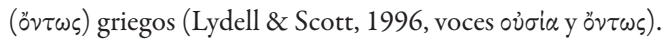


tramos y que son de suma importancia para la filosofía: el primero, el problema de la verdad; y el segundo, el problema de las apariencias. Ambos relacionados con el mundo de la metafísica, pues buscan responder al problema de la realidad (Garret, 2011, p. XVII).

Precisamente, Gorgias de Leontino, teniendo en cuenta la relación de estos dos elementos -a los que les suma el lenguaje-, refuta la tesis de Parménides, relacionando el ser con la apariencia y sintentizando su crítica en esta tesis: "El primero es, que nada existe; el segundo, que, aún en el caso de que algo exista, es inaprehensible para el hombre; y el tercero, que, aún cuando fuera aprehensible, no puede ser comunicado ni explicado a otros" (DK, 80 B 3).

Es de notar la interesante relación entre el ser y el conocimiento y cómo pasa por esos "filtros" hasta llegar al lenguaje; decimos "filtros", porque puede haber cosas que sean (o sea, que existan) y no se puedan conocer; además, cosas que conozcamos y no podamos comunicar. Luego, la jerarquía queda establecida, y ese es el aporte del famoso sofista: cómo preguntarnos por el ser, pasando por la metafísica, la gnoseología, la epistemología, y, por último, la filosofía del lenguaje.

Por otra parte, Parménides expone, a través de la diosa, dos vías de investigación. Nos manifiesta que "la primera, que Es y que no es No-ser [...]. La otra, que no es y es Necesariamente No-ser" (DK 28 B 2, 1-5). Lo que se nos manifiesta expresamente y lo que se da por sentado pertenecen al orden de la lógica: lo que es es (existe), y lo que no-es no es (no existe). Se da por supuesta entonces la existencia del ser en tanto existente; en Parménides -y en Sartre, como se verá posteriormente- el ser lógico y el ser en tanto que ente se traslapan sobre sí de una manera evidente.

Sartre no es ajeno a esta visión, pues, sin lugar a dudas, el filósofo francés parte del fenómeno -y con ello no estamos diciendo que el ente y el fenómeno 9

9 Fenómeno proviene de phainetai ( $\phi \alpha i v \varepsilon \tau \alpha \mathrm{l}$ ), que significa "salir a la luz, lo evidente, manifiesto, lo que se aparece [así como también] lo aparente (opuesto a lo verdadero)” (Lydell \& Scott, 1996, voz $\phi \alpha i v \omega)$. Comúnmente se utiliza el término fenómeno para aludir no solo a representaciones mentales, sino también a hechos sociales (fenómeno social, cultural, etc.); sin embargo, en el campo de la fenomenología se asume de una manera especial; dice Husserl (2013): "por distinta que pueda parecer la palabra fenómeno en semejantes expresiones, y sean cuales fueren las significaciones que pueda aún tener, lo cierto es que también la fenomenología se refiere a todos estos fenómenos y según todas las significaciones: pero en una actitud totalmente distinta, mediante 
sean lo mismo, más bien que el fenómeno es la manifestación misma del ente-, al que llama el "existente". De esta forma, hace un recorrido en el que nos muestra cómo el pensamiento moderno ha hecho un esfuerzo por "reducir el existente a la serie de las apariciones que lo manifiestan” (Sartre, 1993, p. 15); es decir, por buscar el monismo entre los múltiples dualismos que la filosofía ha construido a lo largo de la historia.

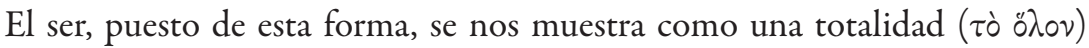

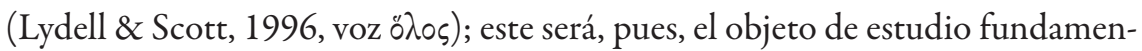
tal en la obra sartreana; pero, en este caso, un ser basado en el fenómeno. "Lo que el fenómeno es, lo es absolutamente, pues se devela como es. El fenómeno puede ser estudiado y descrito en tanto que tal, pues es absolutamente indicativo de si mismo" (Sartre, 1993, p. 16).

¿Cuáles son las razones que llevan a Sartre a afirmar tal cosa? El ser desde el cual trabaja Sartre es netamente óntico (es decir, el ser desde el ente), no es el puro ser o la pura nada. El ser y la nada que él estudia abren posibilidades al conocimiento; son cognoscibles de manera mediata a partir de la existencia. Este es el ser en tanto que ser determinado (Dasein) por el pensamiento y la acción. Por tal razón, El ser y la nada no es un texto en el que se intente hablar del ser y la nada en cuanto tales, pues ambos exceden por sí mismos el espacio de lo cognoscible. Dice Hegel:

El puro ser y la pura nada es lo mismo. Lo que es la verdad no es ni el ser ni la nada, sino el hecho de que el ser, no es que pase, sino que ha pasado a nada, y la nada a ser. Pero, justamente en la misma medida, la verdad no es su indiferencialidad, sino el que ellos sean absolutamente diferentes; pero justamente con igual inmediatez desaparece cada uno dentro de su contrario. Su verdad es pues este movimiento del inmediato desaparecer del uno en el otro: el devenir; un movimiento en donde ambos son diferentes, pero mediante una diferencia disuelta con igual inmediatez (Hegel, 2011 [WdL], B. 1, S. 45).

Según lo anterior, pensar en el puro ser y la pura nada promueven una visión óntica de la realidad, mas no es la realidad misma, ya que la realidad es realidad

la cual se modifica en determinada manera cada uno de los sentidos del término fenómeno con que nos encontramos con las ciencias que nos son familiares desde antiguo. Solo en cuanto modificado de esta suerte entra el fenómeno en la esfera fenomenológica" (Hua III/1,3). 
por la relación que se establece entre la existencia y el espíritu humano: "lo que es racional, eso es efectivamente real [wirklich], y lo que es efectivamente real [wirklich], eso es racional" (Hegel, 2017, \$6;2010b, p. 21). Este axioma también es defendido por Sartre; explicando, además, que esto no indica que el ser y lo racional sean una misma $\cos ^{10}$, sino que lo racional o lo irracional es algo que se devela sobre el ser:

El principio de identidad no es sino una especificación de un principio mucho más general y fundamental (el principio de identidad es regional), el de que el Ser es cognoscible. Y eso no significa en absoluto que el Ser sea racional, o sea, que se pliegue a un cierto número de leyes unificadoras, sino simplemente que, racional o irracional, puede desvelarse en su racionalidad o irracionalidad (Sartre, 2013, VE, 13).

En este orden de ideas, la filosofía sartreana del ser es una "filosofía de la conciencia" que requiere un reconocimiento de la realidad en tanto que racional. Por eso prevalece la importancia de lo aparente como lo existente y como lo que se presenta o lo que se da al conocimiento humano por encima de la definición tradicional de apariencia. "La apariencia remite a la serie total de las apariencias y no a una realidad oculta que habría drenado para sí todo el ser del existente” (Sartre, 1993, p. 16).

Encontramos en esta posición sartreana una visión fenomenológica husserliana -incluso, con matices del idealismo hegeliano-, pues es propio de la fenomenología partir de lo que se presenta, de lo que se es dado; "tener originariamente dado algo real, percatarse de ello y percibirlo en una simple intuición, son una sola cosa" (Husserl, 2013, vol. 1, § 1; Hua III/1, p. 11). Es claro que esta interpretación de apariencia posee otras posturas negativas, como la de Platón (Sof.);

10 La diferencia entre existencia y realidad planteada por Hegel ya ha sido explicada anteriormente (Hernández, 2016, p. 25). Existir y ser real se distinguen en que el último concepto tiene una carga semántica; Wirklich (ser real) es reemplazable por Warheit (ser verdadero); Realität, por otra parte, es reemplazable por existencia. Realität designa a las cosas en sí mismas, pero previa a cualquier "dotación de sentido". La realidad, en el sentido de Wirklichkeit, es todo aquello que es apropiado por el espíritu (o conciencia) y que es reconocido por este como verdadero (Fuentes Morán, 2002, voces Realität y Wirklichkeit). Para profundizar en esta caracterización de la realidad como algo conceptual (en el amplio sentido de concepto [Begriff]), pero a la vez como algo cambiante y dinámico, véanse los aportes de Zubirí (1985, 1995). 
sin embargo, vale resaltar que de fondo el fenómeno se devela y devela lo que es (no puede develar lo que no es); es decir, el fenómeno se aparece. Por esa razón, el fenómeno es indicativo de sí mismo. De esta manera, lo fundamental es la apariencia en tanto que es lo que se me aparece. La apariencia toma en Sartre un valor positivo. En Parménides las cosas no cambian del todo, pues "las apariencias ha sido necesario que sean probablemente ${ }^{l l}$ [...] Es y no es No-Ser" (DK, 28 B 1-2).

Con esta resignificación del concepto de apariencia encontramos, pues, la primera diferencia entre Sartre y Parménides. En Sartre es la vía de acceso al ser, no en tanto una opinión, sino en tanto manifestación; "la apariencia se aparece". Así, el ser sartreano no se presenta como una irrealidad o como un mundo suprasensible.

La apariencia remite a la serie total de las apariencias y no a una realidad oculta que habría drenado para sí todo el ser de lo existente. Y la apariencia, por su parte, no es una manifestación inconsistente de ese ser [...], su esencia es un "parecer" que no se opone ya al ser, sino que, al contrario, es su medida. Pues el ser de un existente es, precisamente, lo que parece (Sartre, 1993, p. 16).

Por otro lado, Parménides abre una brecha al decirnos "probablemente", pero su postura a lo largo del Poema tiende más hacia el sentido negativo de apariencia. Teniendo en cuenta esto, posteriormente Platón nos lleva a una aporía -a un camino sin salida- mostrándonos el trasfondo que se oculta en esa "probabilidad" de aceptar lo aparente como algo que es o que devela el ser:

Ext. Mas decir el que habla mentira, o estimar que la mentira en realidad es, y al proclamarlo no ser cogido en contradicción, es dificilísimo, Teeteto.

Tee. ¿Por qué?

Ext. Porque tal modo de razonar tiene el atrevimiento de dar por supuesto que lo que no es es, pues de otra manera no podría llegar a ser lo falso (Sof., 237e4-237a5).

11 Creemos que este sentido negativo del fenómeno ( $\phi a \iota v o ́ \mu \varepsilon v o v)$ se debe a una asociación de este con la opinión $(\delta \circ \xi \alpha)$, bastante criticada por Heráclito, Parménides y Platón. Si bien es cierto que algunas apariencias pueden ser engañosas, vagas o imitaciones ( $\mu i \mu \eta \sigma \zeta$ ), no todos los fenómenos lo son, pues sin los fenómenos no sería posible la contemplación de las ideas y de esa "verdad bien redonda" de la que habla Parménides. 
Ante esto, nos da la sensación de que para Platón es inconcebible que la apariencia sea; no obstante, más adelante nos dice: "Ext. Pues para nosostros es evidente que la palabra algo la decimos siempre con referencia a lo que es; pues decir esto solo cuando está desnudo y privado de todo ser, es imposible, ¿no es verdad? Tee. Imposible" (Sof., 237d). La paradoja se da en que la apariencia es apariencia de algo, y necesariamente, eso que decimos que es algo: es. La apariencia es, ya que es la copia de la referencia, de lo verdadero, de la idea.

Queda en nosotros una pregunta fundamental que la filosofía se ha hecho con miras a un análisis o estudio sobre el tema de la realidad: ¿qué es la apariencia?, es más, ¿la apariencia es o no es, o bien, es y no es? Desde el poema de Parménides, la diosa desea enseñarle al viajero un modelo ${ }^{12}$ (lo que nosotros llamaríamos un método) para encontrar la verdad; un modelo que funcione para identificar lo que es. Como lo expresamos anteriormente, la diosa no niega la existencia de las apariencias, antes bien, las reúne todas en un cúmulo de "opiniones" que no son la realidad (Platón, Rep., 478b; Sof., 188e y ss.).

Teniendo en cuenta las relaciones mencionadas anteriormente entre el lógos

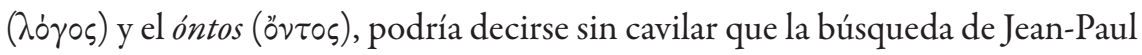
Sartre es el reestablecimiento de la relación conciencia-mundo; es decir, restablecer el vínculo de lo que se me aparece a mí como hombre en el mundo con lo que el mundo mismo es. Por ello, podríamos decir que en Sartre se hace patente la famosa invitación husserliana a "ir a las cosas mismas", ya que la apariencia remite al fenómeno, y el fenómeno es la manifestación tética del ente mismo. Aunque vale aclarar que el ente en Sartre no tiene por objeto una develación, su fundamento y determinanción es la existencia, y no posee pretenciones ante el sujeto; es decir, es plena existencia $(\tau \tilde{\omega} \nu$ ő $v \tau \omega \nu)$. Empero, si hacemos énfasis en

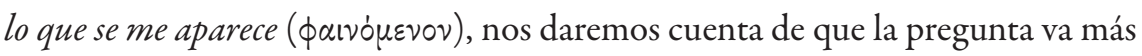
allá del ser determinado (la existencia) e incluso se encuentra en el عőv (lo que es) del eléata, que alude a una concepción más compleja (la realidad). Dicen Kirk, Raven \& Schofield (2014):

12 Esto sería en Platón el referente $(\pi \alpha \rho \dot{\alpha} \delta \varepsilon 1 \gamma \mu \alpha)$ de la idea del Bien $\left(\dot{\alpha} \gamma \alpha \theta_{o v}\right.$ i $\left.\delta \dot{\varepsilon} \alpha\right)$ que tomó el Demiurgo para ordenar el cosmos (Tim., 29c-34a; Sof., 235b10-236d8). 
Cuando más tarde (p. e., 297, 22-55; 299, 46-48) emplea el participio eon, “ente”, es mucho más fácil interpretarlo como "realidad" o "lo real” que como mero indicador de existencia. Lo que otorga realidad a algo es, sin duda, lo que posee algún predicado verdadero (p. e., “ocupa espacio”). Si esta línea de interpretación es correcta, el uso parmenídeo de estín es simultáneamente existencial y predicativo (como sostuvo DK), pero no mezclados por esta razón (como concluyó DK) (p. 327).

Ahora bien, esa búsqueda del ser en Sartre se reduce a un solo dualismo a través de los dualismos de la metafísica: las cosas o los fenómenos en tanto finitud e infinitud de las manifestaciones, develaciones o apariciones del ser; pues con ello se apuntaría a una idea pura y única del ser.

Lo existente, en efecto, no puede reducirse a una serie finita de manifestaciones, puesto que cada una de ellas es una relación a un sujeto en perpetuo cambio. Aun si un objeto se revelara a través de una sola Abschattung, el solo hecho de ser sujeto implica la posibilidad de multiplicar los puntos de vista sobre esa "abschattung" [sic]. Esto basta para multiplicar al infinito la "abschattung" [sic] considerada (Sartre, 1993, p. 17).

Hay así una infinitud en la serie de manifestaciones que presenta o que devela el fenómeno o existente; o sea que no habría una sola y única verdad sobre el ser, que en este caso es el tema que nos atañe.

Sartre hace alusión a Husserl con la palabra alemana Abschattung, que traduce "sombreado" en el lenguaje habitual, pero que Husserl trabaja como un aspecto mismo del objeto; o sea, esa "parte" que el objeto en tanto que objeto deja ver y que no es la totalidad del objeto mismo ${ }^{13}$. Por esto, serían infinitas las manifestaciones del objeto y se plantearía este dualismo de finitud e infinitud en el existente. Sale, entonces, a relucir de manera moderada ese relativismo protagórico que afirma: "el hombre es la medida de todas las cosas, de las que son, puesto que son, de las que no son, puesto que no son" (DK 80 B 2). La verdad no es, pues, algo constitutivo de las cosas, sino que es el aparecer de estas en tanto que real.

13 Esto lo toma Husserl de lo que Kant llama "el giro copernicano". Dice Kant (2011b): "representar un concepto puro del entendimiento como pensable en un objeto fuera de la experiencia posible significa procurarle realidad objetiva, y, en general, exhibirlo. Cuando no se puede hacer esto, el concepto es vacío, esto es, no es suficiente para un conocimiento" ( $A k$., XX, 279). 
“Toda realidad [Wirklichkeit] existe por obra de un dar sentido" (Husserl, 2013, vol. 1, §55; Hua III/1, 11).

Sin lugar a dudas, hay varios puntos de unión entre Parménides y Sartre. Para el eléata lo ente o el ser tiene unas características claras, entre ellas: "es ingénito e imperecedero $[\ldots]$, completo $[\ldots]$, continuo $[\ldots]$, inmóvil $[\ldots]$, inmutable $[\ldots]$, semejante a la masa de una esfera bien redonda" (DK, 28 B 8, 1-40). Es decir, el

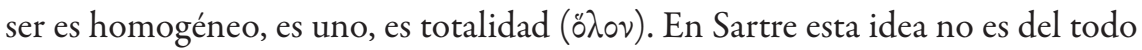
opuesta, pues "[...] la totalidad no puede venir a los seres sino por un ser que ha de ser en presencia de ellos su propia totalidad. [...] Así, la totalidad conclusa o mundo se devela como constitutiva del ser de la totalidad inconclusa por la cual el ser de la totalidad surge al ser" (Sartre, 1993, pp. 210-211).

Casi que a modo de trabalenguas nos dice Sartre que el ser uno es dado en el mundo por un ser que en si mismo es uno; no se desliga de la idea de que el ser es y que no puede ser otra cosa que lo que es. Por ello, el hombre -que, en sí mismo, es un todo- puede engendrar el ser de la totalidad por la conciencia (Sartre, 1993, pp. 107 y ss.).

Por otra parte, si tenemos en cuenta esa multiplicidad infinita de fenómenos oformas de develamiento del ser se puede tomar al fenómeno como infinito, como plural. Así, si el ser en sí mismo es uno (uóvos), las representaciones son múltiples ( $\pi \circ \lambda u ́ s)$. Empero, si la única forma de conocer el ser es por medio de las representaciones, ¿cómo podremos llegar a esa unidad a pesar de la multiplicidad que está implícita en nuestras representaciones?

La respuesta a la anterior pregunta la sitúa Sartre en el sujeto: el fenómeno se nos presenta desde una finitud porque el sujeto que lo experimenta es finito temporal y corporalmente (existencialmente). Es por esto que el punto medio entre la unidad total del ser y la multiplicidad infinita de los fenómenos es el hombre. Es necesario que sea trascendido a la serie infinita de las manifestaciones para poder alcanzar ese ser de la totalidad que no señala otra cosa que el mundo real objetivo. Así nos damos cuenta de que esta “[...] teoría del fenómeno ha reemplazado la realidad de la cosa por la objetividad del fenómeno, y que ha fundado esta objetividad sobre un recurso al infinito" (Sartre, 1993, p. 17). Es esto lo que explica por qué el hombre y su condición existencial toman un papel predominante en su metafísica: el hombre es el punto de unión entre el ser y el fenómeno. 


\section{El fenómeno de ser y el ser del fenómeno}

ESTE ES APENAS EL INICIO de la teoría del ser sartreana. La pregunta a resolver derivada de ese primer aparatado ontológico es: ¿cuál es el ser de ese a-parecer? El poema Sobre la naturaleza de Parménides plantea que "lo Ente es; pues es el Ser, pero la Nada no es" (DK, 28 B 6, 1). Es decir, el ser existe; y existe porque su esencia es la existencia. Es la primera conclusión a la que hemos llegado con Parménides.

Ya al final de la primera parte de la introducción de El ser y la nada, Sartre (1993) nos dice: "si la esencia de la aparición es un aparecer que no se opone a ningún ser, hay ahí un legítimo problema: el del ser de ese aparecer" (p. 18). Es decir, ¿cuál es el ser cuya esencia es "a-parecer" o "existir"?

Anteriormente manifestamos que el ser sartreano es fenoménico -fue el primer acercamiento con el ser-, pero nos estaríamos enfrentando con ello a la finitud y al devenir que esos fenómenos implican; lo cual lleva a una dicotomía entre la unidad del ser y la multiplicidad del aparecer de ese ser (el fenómeno). Ante esto, dice Sartre (1993):

Husserl ha mostrado cómo siempre es posible una reducción eidética, es decir, cómo se puede siempre ir más allá del fenómeno concreto hacia su esencia; y para Heidegger la "realidad humana" es óntico-ontológica, es decir, puede siempre trascender el fenómeno hacia su ser. Pero el tránsito del objeto singular a la esencia es tránsito de lo homogéneo a lo homogéneo (p. 18).

Podemos decir que hasta aquí no hemos sido capaces de encontrarnos cara a cara con el ser; pues, si bien hemos dado características, no hemos podido encontrar el gozne que nos lleve a la realidad del ser: el ser en cuanto unidad total. Hemos tenido, tal vez, un acercamiento cronotópico ${ }^{14}$ al ser; empero, ¿dónde queda ese ser más allá o "detrás" de lo físico, que es uno, que es totalidad, que es infinito (o sea, el metafísico)? Es evidente que este problema filósófico parte del

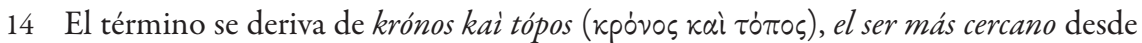
el tiempo y espacio (el del factum). Es decir, que hemos analizado aquella región del ser que está en constante devenir (aquella región que es y no es) (Hegel, 2011, B. I, $S .54-55)$, pero no nos hemos preguntado por la totalidad del ser, por lo que es en tanto que es ( $\tau$ ò oैv ที oैv) (Aristóteles, Met., Г, 1, 1003a20). 
pensamiento griego, como lo manifestamos anteriormente, pero ¿nos es dado conocerlo?

Hay un ser que es y es más allá de las cosas mismas; con Parménides, diríamos que "lo Ente toca a lo Ente" (DK 28 B 8, 25). Por ello, el ser -que en este caso

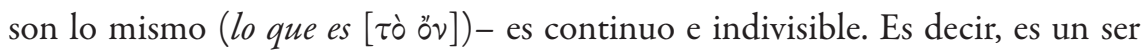
trascendental ${ }^{15}$. Al volver al pensamiento de Sartre nos encontramos con que debe haber un fenómeno del ser; una "a-parición” de ese ser. Porque, si bien el ser como totalidad es trascendental, su presencia como unidad en lo múltiple es innegable: "lo ente es". Es la necesidad de pensar "lo múltiple” respecto a "lo Uno" lo que nos ha llevado a analizar ontológicamente la realidad, ya que lo Uno está implícito esencialmente en lo múltiple porque de este (lo Uno) es que ha emanado (Plotino, 1996, VI, 9).

No obstante, el problema realmente importante y de trasfondo es: ¿dónde podemos hallar una prueba ontológica que nos revele la existencia de ese ser trascendental? Ya habíamos aclarado que el fenómeno me debe remitir a un algo, pues incluso la apariencia es apariencia de algo; empero, ese ser es indeterminado, no tenemos certeza de qué es ese trasfondo que estamos buscando. Así, podría darse el caso de que eso indeterminado nunca pueda develarse, que sea incognosible en virtud de su naturaleza primitiva e incondicionada.

Según lo anterior, si queremos llegar al ser en cuanto totalidad, debería existir un fenómeno que nos devele esa serie al infinito de manifestaciones y que podamos llamar ser en el sentido absoluto del término.

La esencia no está en el objeto, sino que es el sentido del objeto, la razón de la serie de apariciones que lo develan [...]. El objeto no remite al ser como a una significación: sería imposible, por ejemplo, definir el ser como una presencia,

15 Entiéndase trascendental distinto de trascendente. El ser trascendente es aquel cuyos principios provienen fuera de sí, incluso, fuera de la naturaleza: Dios. Es un ser, por así decirlo, de trasmundos o sobrenatural. Por otra parte, inmanente indica que los principios son intrínsecos, lo cual implica que sus principios son intrínsecos. Ahora bien, se dice que algo es trascendental cuando se reconoce que los principios están "más allá” de lo existente, pero se estudian a partir de su propia naturaleza; es decir, es intermedio entre la postura trascendente e inmanente. Kant explica este concepto bajo la pregunta: ¿cuáles son las condiciones de posibilidad para que esto exista? Lo trascendental transforma el adverbio metá ( $\mu \varepsilon \tau \dot{\alpha})$ de la metafísica para encontrar ese "más allá" desde lo esencial y substancial del ente mismo (Kant, 2011a $[K r V]$, B XIX). 
puesto que la ausencia devela también al ser ya que no estar abí es también ser. El objeto no posee al ser [...]. Decir es es la única manera de definir su manera de ser (Sartre, 1993, p. 19).

Ahora bien, cuando hablamos del ser en el sentido más amplio, el fenómeno del ser no es el objeto mismo, sino que estamos ante un problema de "sentido". Buscar el sentido es la razón final del conocimiento sobre el objeto para vislumbrar el ser desde allí. Buscar la esencia del ser es buscar el sentido de "la cosa". Así, "la cosa" no es más que "la cosa misma"; v. gr:: una piedra no nos remite sino a la piedra misma (el fenómeno), pero no nos remite al ser. El fenómeno del ser es la cosa trascendida, llevada a la infinitud de sus manifestaciones. Su manera de ser

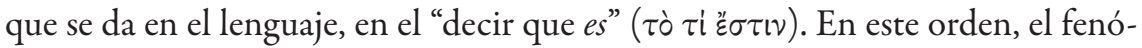
meno de ser es "transfenoménico", o sea, no posee un fenómeno concreto que lo manifieste, sino que pretende ser universalizable a partir del concepto.

Entonces, desde estos precedentes, buscar el ser implica la inmanencia, y es aquí donde empieza a jugar un papel preponderante la conciencia, pues es ella la que nos dará la prueba ontológica del ser. Sartre (1993) nos dice: "toda conciencia es conciencia de algo" (p. 29). Pues bien, se nos plantean dos opciones para entender esta premisa: la primera, que toda conciencia es constitutiva del ser de su objeto; y la segunda, que la conciencia es relación con un ser trascendental.

Cuando hablamos de que "somos conscientes de algo", la preposición de pertenencia de la oración $(d e)$ nos remite necesariamente a un exterior, a un "[...] estar frente a una presencia plena y concreta que no es la conciencia" (Sartre, 1993, p. 29). Entiéndase con esto que no se busca reducir la realidad dentro de la subjetividad -esto sería un idealismo solipsista, y no es la idea de Sartre-; de hecho, lo expresa de la siguiente manera: "jamás lo objetivo saldrá de lo subjetivo, ni lo trascendente de la inmanencia, ni el ser del no-ser” (p. 30). Más bien, lo real (Wirklichkeit) alude al campo fenoménico (el ser del fenómeno) que ni se reduce a la existencia pura, ni se enfrasca en la representación del sujeto. Esta idea tiene su génesis en Husserl (2013):

A quien en vista de nuestras discusiones objete que esto significaría convertir todo mundo en ilusión objetiva y echarse en los brazos de un "idealismo berkeleyano", sólo podemos replicarle que no ha captado el sentido de estas discusiones. [...]. No se "interpreta", ni menos se niega, la realidad real, sino 
que se desecha una interpretación de ella que entraña un contrasentido, esto es, que contradice su propio sentido intelectivamente aclarado. $(\$ 55, \mathrm{Hua}$ $I I I / 1,120)$

Casi que del mismo modo como nos habla Parménides en su poema, diciéndonos acerca del ser: “[...] ¿qué nacimiento le buscarías? ¿Cómo, de dónde

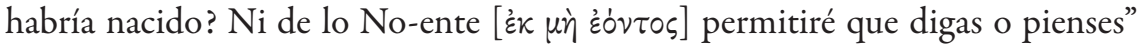
(DK, 28 B 8, 5). De esta manera, Sartre pone la trascendencia (en el sentido de "trascendental") como la estructura constitutiva de la conciencia. En palabras de nuestro autor: "La conciencia nace apuntando hacia un ser que no es ella misma. Es lo que llamamos la prueba ontológica [...]. Debe producirse como revelación revelada de un ser que no es ella misma y que se da como ya existente cuando ella lo revela" (Sartre, 1993, pp. 30-31).

Sartre se planta en la subjetividad, que define como "conciencia de conciencia”. Así, cuando hablamos de subjetividad, nos referimos a una intuición revelante y, por lo mismo, un revelado. De esta forma, la inmanencia no puede definirse sino en la captación de un algo trascendental (el ser).

Bajo estos parámetros, volvemos al inicio de nuestra investigación y planteamos: ¿qué es la conciencia? ¿Es esa prueba que nos brinda la infinitud de las manifestaciones del ser? Puede ser, al menos, “[...] un ser cuya existencia pone la esencia, e, inversamente, es conciencia de un ser cuya esencia implica la existencia, es decir, cuya apariencia exige ser" (Sartre, 1993, p. 31).

De esta manera, vemos cómo sigue habiendo puntos de unión entre el ser parmenídeo y el ser sartreano; no podemos olvidar que, para Parménides, “[...] lo mismo es el pensar y el ser" (DK, 3,1$)$, pero no en el sentido del idealismo -en el que el pensamiento es la esencia-, sino en la unidad del todo exterior a la realidad de la persona ${ }^{16}$.

Ya en Sartre la conciencia de la subjetividad -es decir, "la conciencia (de) conciencia"- se convierte en la "prueba ontológica del ser". Sartre asimila la definición de Dasein de Heidegger (2014, pp. 12-13) y la concluye así: “[...] un

16 La postura de Parménides es, por así decirlo, más bien ecléctica: no restringe plenamente el ser a la idea -una postura netamente racionalista/idealista (Zenón)-, pero tampoco el pensar al ser, cayendo en un materialismo exacerbado (cosa que sí afirma Meliso) (Guthrie, 1991, vol. 2, pp. 93-130). Ser e idea se implican entre sí, pero no son reducibles. 
ser para el cual en su ser está en cuestión su ser en tanto que este ser implica un ser diferente de él mismo" (Sartre, 1993, p. 31). Así, pues, se nos hace explícito el sentido trasfenoménico de los fenómenos.

\section{El "ser-en-si"17}

"La CONCiencia es CONCIENCIA De algo", nos dice Sartre; este problema metafísico desemboca en la conciencia misma; por ello, también la conciencia es revelación-revelada y las cosas están frente a la conciencia por "el ser que les es propio". No se les puede despojar a los existentes el ser que les es dado en la existencia. Los existententes están ahí, frente a la conciencia, sin el ánimo de develarse por sí mismos a la conciencia. "No hay ser que no sea ser en una manera de ser y que no sea captado a través de la manera de ser que a la vez lo pone de manifiesto y lo vela" (Sartre, 1993, p. 32).

Como lo expresamos anteriormente, la conciencia puede sobrepasar el ser del existente (pero no hacia su ser, sino hacia el sentido); aquí, entonces, Sartre se vale de la visión heideggeriana según la cual la realidad humana es onticoontológica (Heidegger, 2014, pp. 10-11). Se pasa de la cosa misma a la conciencia que encuentra el sentido de "la cosa" y que entraña el fundamento del mismo ser. Desde allí podríamos decir que Sartre absolutiza el sentido del ser: "el sentido del ser vale para el ser de todo fenómeno, comprendido el suyo propio" (Sartre, 1993, p. 32). ¿Cuál es, pues, el sentido del ser?

Sartre critica el creacionismo - la idea de que Dios lo crea todo de la nada (creatio ex nibilo) (BJ, 2 Mac., 7, 28)- afirmando que esa relación le quita "independencia" al ente, pues las cosas estarían frente a una subjetividad divina y no les quedaría otro paso que buscar fundirse de alguna manera (mística) en esa misma subjetividad (Eckhart, 2008). Podemos notar que con ello hace una crítica a cualquier postura que sostenga la pérdida de condición libre del individuo en tanto tal.

17 Sartre retoma dicho concepto de la misma manera que Hegel: como "lo dado". El en sí viene a ser, pues, la forma positiva bajo la cual las cosas son, y el para sí, el desenvolvimiento que dicha forma hace sobre sí negándose en tanto que devenir (la autoconciencia) (Hegel, 2017, $\$ 92 ; \S \S 385-386$ ). 
Aunque hubiese sido creado, el ser-en-sí sería inexplicable por la creación, pues asume de nuevo su ser más allá de ésta. Esto equivale a decir que el ser es increado. Pero no ha de concluirse que el ser se crea a sí mismo, lo que supondría que es anterior a sí. El ser no puede ser causa sui a la manera de la conciencia. El ser es en sí(Sartre, 1993, pp. 33-34).

El ser es "en-sî", en el sentido de "sí mismo"; no es actividad ni pasividad. Para nuestro autor estas dos nociones o categorías son propiamente humanas y, evidentemente, en el caso creacionista estamos hablando de "un ser más allá de lo bumano”. El ser, entonces, es lo que es; es una síntesis (objeto-sujeto/ser-fenómeno/ unidad-multiplicidad). No se puede decir, como lo indica Parménides, que el ser sea otra cosa que lo que es; o sea, lo que existe en general. Las capacidades lingüísticas nos han de llevar a afirmar que el ser “ha-de-ser lo que es” (Sartre, 1993, p. 35). De esta manera, se denota con toda claridad el ser parmenídeo en esta visión sartreana. Ya lo habíamos notado con sus características y con algunas nociones, pero es en este punto donde se unen del todo estas dos posturas acerca del ser:

Desde el momento que existen seres que han de ser lo que son, el hecho de ser lo que se es no es en modo alguno una característica puramente axiomática: es un principio contingente del ser en sí. En este sentido, el principio de identidad, principio de los juicios analíticos, es también un principio regional sintético del ser (Sartre, 1993, p. 35).

Vemos, pues, en estos planteamientos un ser que no es del todo hermético; que simplemente es para existir, aunque Parménides expresamente quiera verlo como una masa esférica impenetrable (que es el todo). En Sartre, el hecho de que "sea todo" no lo hace inaccesible; el fenómeno (que es su forma de expresión) es lo que lo devela.

Cuando se nos dice que "el ser es. El ser es en sí. El ser es lo que es" (Sartre, 1993, p. 36), en últimas, se nos está hablando de “las cosas mismas", de la síntesis de las manifestaciones en las que nos puede ser dado un objeto. La conciencia encuentra al ser que no está expectante -el ser encontrado o revelado-, sino que, al contrario, está ahí y la conciencia lo capta; empero, no es para ser captado; es simplemente "una cosa ahi" frente a la conciencia.

A nuestro modo de ver, nos hemos adentrado en el ser de la subjetividad porque, en últimas -aunque los fenómenos se den a la conciencia per se-, es la 
conciencia la que está brindando el sentido al ser. El ser es "ser en-si" porque la conciencia ha logrado definirlo como un "en-si", como síntesis. Es la conciencia la que logra sobrepasar el fenómeno a la infinitud de sus manifestaciones, volverlo transfenoménico y nombrarlo como "el ser".

\section{Conclusión: el aporte de la propuesta sartreana}

UNA VEZ PRESENTADO EL PROBLEMA y las relaciones entre el ser, el fenómeno, la apariencia y la existencia, ha quedado más claro cuál es la concepción metafísica de Sartre y algunas posibles relaciones con referentes previos. Sin embargo, queda todavía la pregunta: ¿cuál es el aporte genuino de Sartre al campo de la metafísica? Retomemos los problemas metafísicos mencionados y recordemos las respuestas de Sartre:

1. ¿Conocemos las cosas tal cual son, o solo son apariencias?

Respuesta: "Las cosas en sí mismas", como lo mencionó Kant (2011a), son incognoscibles, pero del hecho de que sean representaciones propias (trascendentales) no se sigue que no sean verdaderas, pues la verdad (por no decir "la realidad") es transfenoménica (o, como diría Hegel, "es racional"). Ciertamente, la realidad emerge de la existencia, pero la excede cuando también entra en juego la subjetividad.

2. Si no podemos conocer las cosas mismas, ¿qué garantías tenemos de que existan las cosas mismas y no sean más que un ideal de la razón?

Respuesta: Todo fenómeno es fenómeno de algo; no puede ser causa sui, pues su re-presentación exige siempre un algo al cual se remite o denota. Luego sí existe el fenómeno.

3. Pero, si es cierto que el fenómeno remite a las cosas mismas, ¿cómo es posible que las comprenda, si el ser en su totalidad es Uno y se pueden tener múltiples representaciones de un mismo objeto?

Respuesta: El hecho de que el ser sea esencialmente Uno (como lo afirman Parménides y Plotino) no niega la posibilidad de que sea conocido desde la multiplicidad que generan nuestras facultades. Esto no es un problema fenomenológico, sino de sentido (Sinn). ¿Por qué? Por dos razones: a) porque la condición unitaria del ser le es propia a él y no al concepto que de él tengamos. Su unidad es ontológica, la multiplicidad 
que se genera por nuestras facultades es fenomenológica; b) porque nuestras facultades tienen una tendencia sintética a partir de la abstracción (conceptualización ${ }^{18}$ ) de lo múltiple. Así, la realidad (la verdad de las cosas) es una síntesis fenomenológica entre sujeto y objeto (Hegel, $2011[W d L], B$. I, SS. 63-66).

Así pues, si bien Hegel permitió repensar la metafísica de una manera más cercana, rompiendo con la división tajante entre fenómeno y noúmeno. Sartre, por otra parte, logró reconciliar esta propuesta (la fenomenológica) con su corriente crítica paralela (la metafísico-ontológica) a partir de las relaciones fenómeno-ser, existencia-realidad y subjetividad-objetividad.

Dicho en otras palabras, el aporte de Jean-Paul Sartre en esta área es el de reconciliar al sujeto con el objeto, evitando el conflicto del representacionalismo escéptico antiguo y moderno, y logrando conservar el famoso principio clásico de la propuesta moderna: “[...] yo soy, yo existo, es necesariamente verdadero cuantas veces es expresado por mí, o concebido por la mente" (Descartes, AT, VII, 25).

Partiendo de la complejidad y la importancia de estas preguntas para casi toda la tradición filosófica previa, ¿no parece plausible su aporte? ¿Cómo no tener en cuenta tan importante trabajo, si, desde el inicio, procura sintetizar media tradición filosófica bajo los dos conceptos más antiguos, pero importantes: el ser y la nada?

\section{Referencias}

Aquinatis, s. T. (1951). Summa Theologie. Prima pars. Madrid: Biblioteca de Autores Cristianos.

Aquino de, s. T. (1963). El ente y la esencia. Trad. M. Fuentes Benot. Buenos Aires: Aguilar.

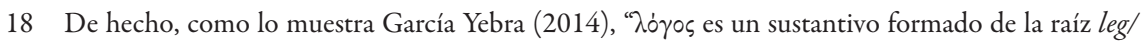
$\log (\lambda \dot{\varepsilon} \gamma \omega / \lambda \dot{o} \gamma \circ \varsigma)$, cuyo significado primero es 'juntar,' 'reunir'” [...]. De aquí se pasó al significado de 'concebir' mentalmente (lat. cum-capio, concipio, con-ceptus)" (p. XXXII). El concepto es una síntesis de propiedades universales bajo una cualidad común $(\exists x \Phi x)$; v. gr: "ser grande", "ser abstracto", "estar determinado", etc. Por ello, el concepto es, por definición, denotativo de la realidad misma, pues él la designa como universal, como síntesis. 


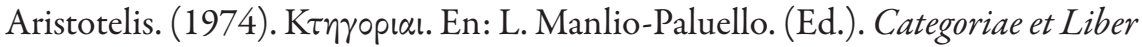
de interpretatione. Oxford: Oxonii e Typographeo Claredoniano.

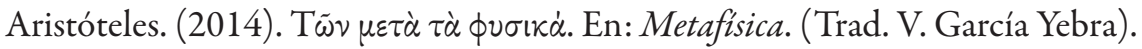
Madrid: Gredos.

Biblia de Jerusalén. (2009). Trad. J. Á. Ubieta. Bilbao: Descleé de Brower.

Descartes, R. (2014). Meditaciones acerca de la Filosofia Primera. (Trad. J. A. Díaz) ( $1^{a}$ ed. en latín). Bogotá: Universidad Nacional de Colombia.

Diels, H. (1912). Die Fragmente der Vorsokratiker, Greihisch und Deutsch. Berlin: Wiedmann. Recuperado de: https://archive.org/stream/diefragmentede01diel\#page/152/mode/2up.

Eckhart, M. (2008). Dios y yo somos uno. En: El fruto de la nada y otros escritos. Trad. A. Vega Esquerra (pp. 51-56)). Madrid: Siruela.

Eggers Lan, C., \& Juliá, V. E. (1981). Los filósofos presocráticos. Tomo 1. Madrid: Gredos.

Fell, J. (1979). Heidegger and Sartre: an Essay of Being and Place. New York: Columbia University Press.

Ferrater Mora, J. (1975). Diccionario de filosofía. Tomo 2. Buenos Aires: Editorial Sudamericana.

Fuentes Morán, M. T. (2002). Diccionario universal alemán. Berlín: Langenscheidt.

García Yebra, V. (2014). Prólogo a: Aristóteles. Metafísica. (Trad. V. García Yebra). Madrid: Gredos.

Garret, B. (2011). What is this thing called metaphysics? New York: Routledge. Gorgias (1999). Sobre lo que no es o sobre la naturaleza. En: Sofistas. Testimoniosy fragmentos. (Trad. A. Melero Ballido). Madrid: Planeta-DeAgostini.

Guthrie, W. K. C. (1991). Historia de la filosofía griega. Tomo 2. (Trad. A. Medina González). Madrid: Gredos.

Hegel, G. W. F. (2010a). [PdG] Fenomenología del espiritu. (Trad. A. Gómez Ramos). Madrid: Abada.

Hegel, G. W. F. (2010b). Lineas fundamentales de la filosofia del derecho. En: V. Rühle. (Ed.). Obras 2. (Trad. M. C. Paredes). Madrid: Gredos.

Hegel, G. W. F. (2011). Ciencia de la lógica. Tomos 1 y 2. (Trad. F. Duque). Madrid: Abada. 
Hegel, G. W. F. (2017). Enciclopedia de las ciencias filosóficas. (Trad. R. Vals Plana). Edición bilingüe. Madrid: Abada.

Heidegger, M. (1997). La pregunta por la técnica. En: Filosofía, ciencia y técnica. (Trads. F. Soler y J. Acevedo). Santiago de Chile: Editorial Universitaria.

Heidegger, M. (2004). ¿Qué es filosofía? (Trad. J. A. Escudero). Barcelona: Herder.

Heidegger, M. (2014). Ser y tiempo. (Trad. J. E. Rivera). Madrid: Trotta.

Hernández, J. C. (2016). El sistema de la ciencia: la filosofía de Hegel. Parresía, 2, 22-32. Recuperado de: http://docs.wixstatic.com/ugd/84dde3_7dd037de53e84b3495d75bada6567ff3.pdf.

Husserl, E. (2008). Crisis de las ciencias europeas y la fenomenología trascendental. (Trad. J. V. Iribarne). Buenos Aires: Prometeo Libros.

Husserl, E. (2013). Ideas relativas a la fenomenología y a una filosofía fenomenológica. Tomo 1. (Trad. J. Gaos). México, D. F.: Fondo de Cultura Económica.

Kant, I. (2011a). [KrV] Crítica de la razón pura. (Trad. M. Caimi). México, D. F.: Fondo de la Cultura Económica.

Kant, I. (2011b). Los progresos de la metafísica. (Trad. M. Caimi). México, D. F.: Fondo de la Cultura Económica.

Kirk, G. S., Raven, J., \& Schofield, M. (2014). Los filósofos presocráticos. Madrid: Gredos.

Lewis C. T., Short, C., \& Freund, W. (Eds.). (1956). Latin Dictionary by Lewis \& Short, Founded on Andrew's Edition of Freund's Latin Dictionary. Oxford: Oxford University Press. Recuperdado de: http://www.perseus.tufts.edu/ hopper/text?doc=Perseus\%3Atext\%3A1999.04.0059\%3Aentry\%3Drevisio. Lydell, H. G., \& Scott, R. (Eds.). (1996). Greek-English Lexicon. Clarendon: Oxford University Press. Recuperado de: http://www.perseus.tufts.edu/ hopper/resolveform? redirect $=$ true.

Parménides (1960). Poema del ser o la naturaleza. En: Parménides. (Trad. F. Montero Moliner). Madrid: Gredos.

Platón (2006). La República. (Trad. J. Pabón, \& M. Fernández-Galiano). Madrid: Centro de Estudios Políticos y Constitucionales.

Platón (2013). Sofista. En: Diálogos: Critón. Gorgias. Menón. Fedro. Sofista. Politico. Cartas. (Trad. A. Tovar). Madrid: Centro de Estudios Políticos y Constitucionales. 
Platón (2014). Timeo. En: Alegre Corrido, E. (Ed.). Obra completa 3. Madrid: Gredos.

Plotino (2006). Enéadas. Tomo 3. (Trad. J. Igual). Madrid: Gredos.

Protágoras (1999). La verdad o Discursos demoledores de Protágoras. En: Sofistas. Testimonios y fragmentos. Trad. A. Melero Ballido. Madrid: PlanetaDeAgostini.

Romero, F. (2005) Culturicidio: Historia de la educación argentina (1966-2004). Buenos Aires: Editorial Librería de la Paz.

Saint-Victor de, R. (1958). De trinitate. J. Rebaillier. (Ed). Paris: Librairie Philosophique J. Vrin.

Sartre, J.-P. (1986). Cartas al Castor y a algunos otros. Trad. I. Agoff. Buenos Aires: Editorial Sudamericana.

Sartre, J.-P. (1993). El ser y la nada. (Trad. J. Valmar). Barcelona: Altaya.

Sartre, J.-P. (2007). El existencialismo es un humanismo. En: C. Gómez Sánchez. (Ed.). Doce textos fundamentales de la ética del siglo XX (pp. 134-162). Madrid: Alianza.

Sartre, J.-P. (2013). Verdad y existencia. (Trad. A. Puleo). Barcelona: Paidós.

Verstraeten, P. (1992). "Appendix. Hegel and Sartre". In: C. Howells. (Ed.). The Cambridge Companion to Sartre. Cambridge: Cambridge University Press.

Zubirí, X. (1985). Sobre la esencia. Madrid: Alianza.

Zubirí, X. (1995). Estructura dinámica de la realidad. Madrid: AlianzaFundación Xavier Zubirí. 